\title{
Nanowhiskers of $\mathrm{K}_{2} \mathrm{Ti}_{6} \mathrm{O}_{13}$ as a promoter of photocatalysis in anatase mesocrystals
}

Alexey A. Sadovnikov ${ }^{\mathrm{a}, \mathrm{b}^{*}}$, Alexey V. Garshev ${ }^{\mathrm{c}}$, Andrei A. Eliseev ${ }^{\mathrm{c}}$, Artemii N. Beltiukov $^{\mathrm{d}}$, Evgeny R. Naranov ${ }^{\mathrm{b}}$, W. Li ${ }^{\mathrm{e}}$, Andrew J. Sutherland ${ }^{\mathrm{e}}$, Olga V. Boytsova ${ }^{\mathrm{a}, \mathrm{c}^{*}}$

a. Kurnakov Institute of General and Inorganic Chemistry of RAS, Leninskii Ave. 31, Moscow, 119991, Russia

b Topchiev Institute of Petrochemical Synthesis, Russian Academy of Sciences, Leninskii avenue, bld. 29, 119991, Moscow, Russia.

c. Department of Materials Science, Moscow State University, Leninskie Gory 1, bld. 3, 119991 Moscow, Russia

d. Udmurt Federal Research Center of UB RAS, T. Baramsinoy 34, Izhevsk, 426000, Russia

e. Aston Institute of Materials Research, Aston University, Birmingham, B4 7ET, UK

*Corresponding authors: Alexey A. Sadovnikov: sadovnikov@ips.ac.ru, Olga V. Boytsova: boytsova@gmail.com,

Phone: +7 (495) 9554125 (3-09); Fax: +7 (495) 633-85-20

\begin{abstract}
Here we describe the development of a new mesocrytalline anatase-based photocatalyst with an activity nearly 2 times exceeding the commercial Evonik Aeroxide ${ }^{\circledR} \mathrm{TiO}_{2} \mathrm{P} 25$ catalyst. An extensive characterization of this new catalytic material with XRD, TEM, SAED, EELS, SEM, RAMAN and XPS shows that its activity is promoted by its hybrid structure comprising mesocrystalline anatase and $\mathrm{K}_{2} \mathrm{Ti}_{6} \mathrm{O}_{13}$ whiskers formed within the $\mathrm{TiO}_{2}$ mesocrystals. This new and unexpected component is formed in situ within the $\mathrm{TiO}_{2}$ mesocrystalline framework at a surprisingly low temperature of $500{ }^{\circ} \mathrm{C}$ as a result of potassium diffusion from polymer-matrix
\end{abstract}


phase. The growth of whiskers occurs at the $001 \mathrm{TiO}_{2}$ planes of mesocrystals and their sizes attain $60 \mathrm{~nm}$ in a section and a few $\mu \mathrm{m}$ in length.

keywords: $\mathrm{TiO}_{2}$ mesocrystals, composites, $\mathrm{K}_{2} \mathrm{Ti}_{6} \mathrm{O}_{13}$ whiskers, hybrid photocatalyst

\section{Introduction}

Mesocrystals, the subject of a recent excellent review [1], may be viewed as macroscopic assemblies of crystallographically-organised nano-sized particles. Critically, the assembled superstructures retain the unique size-related properties of the individual nano-sized building blocks. This, coupled with the fact that their assembly processes are still not fully understood, means that mesocrystals are still the subject of significant research interest despite being first described in 2005 [2]. In the past decade mesocrystalline anatase has been extensively studied, primarily to better elucidate mesocrystal formation processes but also due to its ultimate photocatalytic activity, promoting various utilization from self-cleaning windows to water purification. Microcrystalline $\mathrm{TiO}_{2}$ also holds a promise for various applications including electronic devices, medicine and catalysis. In a recent report we described the formation of anatase mesocrystals from crystalline precursor $\mathrm{NH}_{4} \mathrm{TiOF}_{3}$ and showed that the $\mathrm{TiO}_{2}$ mescocrystals, so formed, exhibited modest photocatalytic activity [3]. Keen to explore and so better understand mesocrystal formation processes we set out to repeat this work and expand it by evaluating $\mathrm{TiO}_{2}$ mesocrystal preparation under a variety of different reaction conditions. Herein we report how this study led to the development of a catalytic system that has better photocatalytic activity than Evonik Aeroxide ${ }^{\circledR} \mathrm{TiO}_{2} \mathrm{P} 25$, a commercial titania-based photocatalyst with high catalytic activity comprising anatase $(\sim 81 \%)$, rutile $(\sim 15 \%)$ and amorphous $(\sim 4 \%)$ titania [4]. Extensive characterisation of this new material showed it to be a composite material of $\mathrm{TiO}_{2}$ mesocrystals bearing whisker-like protrusions of a second crystalline material, $\mathrm{K}_{2} \mathrm{Ti}_{6} \mathrm{O}_{13}$. A number of publications have previously discussed the photocatalytic activity of sodium or potassium 
hexatitanate in the photodegradation reactions of dyes methyl orange [5-7], rhodamine B [8], methylene blue [9], photoreduction of carbon dioxide to formaldehyde and methanol [10-12], photocatalytic water splitting [13,14]. Interestingly, Wu et al. [15] showed that a hybrid material, based on $\mathrm{TiO}_{2}$ and $\mathrm{K}_{2} \mathrm{Ti}_{4} \mathrm{O}_{9}$, had increased photocatalytic activity compared with pure samples of either titanium dioxide or potassium tetratitanate. Regarding synthesis, the formation of $\mathrm{K}_{2} \mathrm{Ti}_{6} \mathrm{O}_{13}$ from $\mathrm{TiO}_{2}$ directly has been reported to typically require reaction temperatures in excess of 800 ${ }^{\circ} \mathrm{C}$ [16-19]. For instance $\mathrm{K}_{2} \mathrm{Ti}_{6} \mathrm{O}_{13}$ can be formed directly from $\mathrm{TiO}_{2}$ and $\mathrm{KF}$ at $720{ }^{\circ} \mathrm{C}$ [20] or from $\mathrm{TiO}_{2}$ via intermediate structures, such as $\mathrm{K}_{2} \mathrm{Ti}_{4} \mathrm{O}_{9}$, at $1150{ }^{\circ} \mathrm{C}$ [21] or $\mathrm{K}_{2} \mathrm{Ti}_{2} \mathrm{O}_{5}$ at $800-1100$ ${ }^{\circ} \mathrm{C}[22]$, as a coating from Ti-foil by anodization in $\mathrm{KOH}$ [23], and by reaction of $\mathrm{Na}_{2} \mathrm{Ti}_{3} \mathrm{O}_{7}$ in $\mathrm{KOH}$ at $250{ }^{\circ} \mathrm{C}$ for 3 days [24].

In this paper, a positive effect of the K-rich photoactive phase in titanium dioxide mesocrystal obtained at low temperatures is proposed.

\section{Experimental}

\subsection{Synthesis}

\subsubsection{General method for the preparation of $\mathrm{NH}_{4} \mathrm{TiOF}_{3} \mathrm{MCs}$}

$\left(\mathrm{NH}_{4}\right)_{2} \mathrm{TiF}_{6}$ (Sigma-Aldrich $\left.\mathrm{UK}\right) \quad 0.1 \mathrm{~mol} \mathrm{~L}^{-1}$ poly(ethylene glycol) PEG-6000 (AlfaChemicals Ltd.) and gelation agent $\mathrm{H}_{3} \mathrm{BO}_{3}$ (Alfa Chemicals Ltd.) $0.2 \mathrm{~mol} \mathrm{~L}{ }^{-1}$ were dissolved in distilled water $(30 \mathrm{~mL})$ under continuous stirring. After full dissolution of the reagents, the resultant gel was kept at $35^{\circ} \mathrm{C}$ for 20 hours. The resultant precipitate was isolated by centrifugation/decantation and subsequently washed with water $(3 \times 20 \mathrm{~mL})$ and acetone $(3 \times 20$ $\mathrm{mL})$.

\subsubsection{General Method for the Preparation of $\mathrm{TiO}_{2} \mathrm{MCs}$}

A sample of $\mathrm{NH}_{4} \mathrm{TiOF}_{3} \mathrm{MCs}$ (ca. $0.5 \mathrm{~g}$ ) was heated in air at $500{ }^{\circ} \mathrm{C}$ for the specified time period (2, 4 or 8 hours). This heating procedure was conducted using a Nabertherm HTCT 03/14 
furnace and exhaust gases were vented into a designated fume cupboard (Caution: Gaseous HF is liberated in this thermally-mediated transformation).

\subsection{Characterization}

X-Ray diffraction (XRD) was conducted on a Bruker D8 Advance system using CuK $\alpha$ radiation. SEM was performed on a Carl Zeiss NVision 40 electron microscope. TEM was performed on a FEI Tecnai G2 F30 electron microscope with resolution of $0.14 \mathrm{~nm}$. Raman spectroscopy was conducted using a Renishaw inVia Reflex spectrometer with an illumination wavelength of $633 \mathrm{~nm}$. BET Low temperature nitrogen adsorption measurements were conducted using an ATX-6 analyzer (Katakon, Russia). Before measurements the samples ( 300 mg weight) were outgassed at $200{ }^{\circ} \mathrm{C}$ for 30 min under a dry helium flow. Determination of the surface area was carried out by the 5-point Brunauer, Emmett and Teller (BET) method at the relative pressure range of $\mathrm{P} / \mathrm{P}_{0}=0.05-0.25$. X-ray photoelectron spectroscopy (XPS) analysis was performed on a SPECS laboratory spectrometer. To excite photoelectrons, magnesium anode X-ray radiation was used $(\mathrm{Mg} \mathrm{K} \alpha=1253.6 \mathrm{eV})$ with a tube voltage of $12 \mathrm{kV}$ and emission current of $20 \mathrm{~mA}$.

\subsection{Photocatalytic test}

To determine the photocatalytic activity of samples, we used a model reaction of methylene blue photodecomposition in an aqueous medium. For each sample photocatalytic activity was measured at room temperature. The photocatalyst $(2 \mathrm{mg})$ was dispersed in $20 \mathrm{ml}$ of aqueous solution of methylene blue dye (concentration of $\mathrm{MB}$ was $40 \mathrm{mg} / \mathrm{L}$ ). Before illumination, the suspension with $\mathrm{MB}$ was stirred in the darkness for $\sim 45 \mathrm{~min}$ to reach the adsorption/desorption equilibrium. The sample was excited in the wavelength range between 320 and $480 \mathrm{~nm}$ using the filtered output of a $300 \mathrm{~W}$ Xe lamp to provide a beam with $1.4 \mathrm{~cm}^{2}$ excitation area and $30 \mathrm{~mW} / \mathrm{cm}^{2}$ excitation power. Aliquots $(1 \mathrm{ml})$ were periodically withdrawn from the reaction mixture. Photocatalysts were separated by centrifugation at 8000 RPM for 10 minutes before UV-Vis analysis.

\section{Results and Discussion}




\subsection{Strategy for the synthesis of the $\mathrm{TiO}_{2}$-based mesocrystals photocatalyst}

Mesocrystalline anatase is readily formed following extended heating (4-8 hours) of $\mathrm{NH}_{4} \mathrm{TiOF}_{3}$ at a temperature of or above $450{ }^{\circ} \mathrm{C}[3,25-29]$. This process typically results in $\mathrm{TiO}_{2}$ crystals that closely resemble the overall morphology of the precursor crystals of $\mathrm{NH}_{4} \mathrm{TiOF}_{3}$. This precursor is formed readily from the reaction between $\left(\mathrm{NH}_{4}\right)_{2} \mathrm{TiF}_{6}$ and $\mathrm{H}_{3} \mathrm{BO}_{3}$ in the presence of a polymer template/promoter such as PEG or BRIJ [30]. The effect of the concentration of PEG6000 on the formation of $\mathrm{NH}_{4} \mathrm{TiOF}_{3}$ and $\mathrm{TiO}_{2}$ mesocrystals was evaluated in our previous article [3]. Specifically, only a 1: 2: 4 molar ratio of PEG-6000: $\left(\mathrm{NH}_{4}\right)_{2} \mathrm{TiF}_{6}: \mathrm{H}_{3} \mathrm{BO}_{3}$, followed by heating yields $\mathrm{TiO}_{2}$ mesocrystals. In the absence of PEG no mesocrystals form, a 1: 4: 8 ratio of reagents leads to the formation mesocrystals with a centralised defect containing nanoparticles of $\mathrm{TiO}_{2}$ whilst a 3: 4: 8 molar ratio furnishes intergrown and aggregated mesocrystals. Accordingly, in this work the optimized 1: 2: 4 reagent ratio (see experimental section) was employed to generate precursor $\mathrm{NH}_{4} \mathrm{TiOF}_{3}$ mesocrystals and the only significant difference being that the final $\mathrm{TiO}_{2}$ samples were to be obtained following heating at the slightly higher temperature of $500{ }^{\circ} \mathrm{C}$ for periods of 2, 4 and 8 hours.

XRD analysis showed that the two samples generated by heating for 2 and 4 hours respectively are single-phase anatase (fig. 1). In contrast, the sample heated for 8 hours is nonsingle-phase being a mixture of anatase and jeppeite phases (fig. 1). Raman spectroscopic data, obtained from single macroparticles, confirms that the 2- and 4-hour samples are pure anatase. Specifically, peaks at 144, 197, 399, 519 and $639 \mathrm{~cm}^{-1}$ all correspond exactly to anatase [31]. The eight-hour sample, in addition to anatase peaks also shows second phase reflections as potassium hexatitanate (fig. 2). Two signals at ca $224 \mathrm{~cm}^{-1}$ and $279 \mathrm{~cm}^{-1}$ are consistent with the production of K-doped material [32] and an analogous Na-doped material [33]. Evidence for $\mathrm{TiO}_{2}$ mesocrystal formation is provided by TEM and SAED (selected area electron diffraction) (fig. 3a,b). For example, material obtained by annealing at 500 degrees for 4 hours, gives single-crystal-like diffraction spots with minor distortion that are typical for mesocrystals (fig. 3b). The presence of 
hexatitanate can be most clearly seen in SEM images (fig. 4d). Micrographs fig. 4b and fig. 4c show only anatase mesocrystals, which differ only in the size of their constituent nanocrystallites, while SEM image fig. $4 \mathrm{~d}$ clearly shows a composite microparticle comprising a $\mathrm{TiO}_{2}$ mesocrystal and nanowhiskers of $\mathrm{K}_{2} \mathrm{Ti}_{6} \mathrm{O}_{13}$. The dimensions of the whiskers, only apparent in the sample heated for 8 hours, are roughly $60 \mathrm{~nm}$ across and between 1-2 $\mu \mathrm{m}$ in length. The evolution of crystallite size of $\mathrm{TiO}_{2}$ nanoparticles was analyzed using both XRD and SEM data (Table 1). According to SEM data, an increase in the annealing time, results in crystallites growing in size from 30 to 90 $\mathrm{nm}$. XRD data is consistent in showing an increase in size with increasing annealing time but, with this technique, a less significant increase from 45 to $53 \mathrm{~nm}$ is observed. Furthermore, it is notable that macroparticle thickness tends to increase with increasing annealing duration. Such a significant growth of crystallites according to the SEM data is most likely associated with the coalescence and growth of nanoparticles on the surface of the mesocrystal, whereas the XRD data relates to the sizes of crystallites within the entire volume of the mesocrystal. Thus, collectively our data and visualisations show, for the first time, the transition from non-classical to classical growth for $\mathrm{TiO}_{2}$ mesocrystals. In summary, it appears that after 4 hours of annealing at $500{ }^{\circ} \mathrm{C}$ degree, $\mathrm{TiO}_{2}$ mesocrystals become unstable and nanoparticles then begin to grow by a classical pathway [1] in all directions.

\subsection{Characterization of the $\mathrm{TiO}_{2}$-hybrid materials}

To understand the root of formation of the composite material, a number of additional analytical techniques were employed. Firstly, XPS analysis (Table 2) confirmed the presence of potassium, likely a contaminant from the PEG [3], in the whiskers and also showed a significant reduction in fluorine had occurred in the final 4 to 8 hours of heating. XRD, TEM, SEM, RAMAN and XPS data collectively led us to conclude that, to our surprise, we had effected a thermallymediated transformation from the parent mesocrystalline anatase into a hybrid $\mathrm{TiO}_{2}-\mathrm{K}_{2} \mathrm{Ti}_{6} \mathrm{O}_{13}$ material with two different crystal phases with very different morphologies being evident. As the annealing duration was increased the reduction of fluorine in the mesocrystals can be the cause of 
instability of the inner pattern followed by lattice disturbance and nucleation of TiOx-structures. The potassium present in the polymer-matrix PEG6000 most probably initiated the $\mathrm{K}_{2} \mathrm{Ti}_{6} \mathrm{O}_{13}$ formation.

According to the TEM, SAED (fig. 5) and EELS data (Table 3), we observe that the nanowhiskers are single-phase potassium hexatitanate. The potassium content is the same along the length of the nanowhisker (fig. 6 and Table 3). We assume that nanowhisker growth occurs as follows - potassium ions diffuse to particles of fluorine-doped $\mathrm{TiO}_{2}$ and the growth of $\mathrm{K}_{2} \mathrm{Ti}_{6} \mathrm{O}_{13}$ occurs according to the classical mechanism [34].

\subsection{Photocatalytic performance}

The presence of potassium hexatitanate in the hybrid highly oriented material prompted us to anticipate that there would be an increase in photocatalytic activity as compared with anatase mesocrystals. To test this hypothesis, a standard photocatalytic assay procedure employing a singlet oxygen mediated-bleaching of methylene blue was conducted on composite samples generated by heating at $500{ }^{\circ} \mathrm{C}$ for 2,4 and 8 hours.

Before the photodecomposition test, concentration change of dye before and after adsorption/desorption equilibrium was measured. There was no obvious decolorizing observed. Although P25 has higher specific surface area and thus larger amount of dye absorbtion was expected, due to small amount of photocatalysts presented in suspension, the amount of dye molecules were highly excessive to the surface area (i.e. surface adsorption sites) of any tested photocatalyst, the difference in absorbed dyes in various photocatalysts was negligible in this test condition.

The photodecomposition results obtained from this study are shown in fig. 7 and show that increased heating times generates material with increased photocatalytic activity. Moreover, the sample formed after heating for 8 hours showed excellent photocatalytic activity that is significantly greater than that of the commercial Evonik Aeroxide ${ }^{\circledR} \mathrm{TiO}_{2} \mathrm{P} 25$ catalyst. This last observation was most surprising since in our previous work [3] we had observed only relatively 
modest photocatalytic activities which increased as the sample heating time increased from 2 to 4 hours at $450{ }^{\circ} \mathrm{C}$ but which decreased again after extended heating (i.e. 8 hours). This loss of activity coincided with a loss of mesocrystalline structural integrity and a concomitant reduction in surface area as assessed by BET. Interestingly, for samples obtained by annealing at $500{ }^{\circ} \mathrm{C}$, the specific surface area does not undergo significant change (Table 1). The probable decrease in the specific surface area associated with an increase in the size of nanocrystallites in the mesocrystal during an increase in the duration of annealing is most likely compensated for by the formation of nanowhiskers.

Analysis of the dye decomposition data revealed that the reactions follow first-order

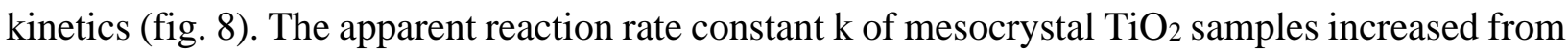
$6.04 \times 10^{-3}$ to $1.74 \times 10^{-2} \mathrm{~min}^{-1}$ when the duration of annealing increased from 2 to 8 hours. The 8 hours annealed $\mathrm{TiO}_{2}-\mathrm{K}_{2} \mathrm{Ti}_{6} \mathrm{O}_{13}$ hybrid showed $86 \%$ higher photocatalytic activity than the commercial photocatalyst Evonik Aeroxide ${ }^{\circledR} \mathrm{TiO}_{2} \mathrm{P} 25$. In contrast, such an increase in annealing time at $450{ }^{\circ} \mathrm{C}$ more than halved the photocatalytic activity [3].

The mechanism of potassium titanate influence definitely worth further investigation. In particular, one dimension and high crystalline nature of $\mathrm{K}_{2} \mathrm{Ti}_{6} \mathrm{O}_{13}$ nanowhisker and heterojunction structured at the interface between $\mathrm{K}_{2} \mathrm{Ti}_{6} \mathrm{O}_{13}$ and $\mathrm{TiO}_{2}$ are being looked into. Both features can enhance photogenerated charge transfer and separation, and thus contribute to promoted photocatalytic activities. Further study will follow to reveal more insights.

\section{Conclusions}

A hybrid material of anatase mesocrystals and potassium titanate $\left(\mathrm{K}_{2} \mathrm{Ti}_{6} \mathrm{O}_{13}\right)$ nanowhiskers with high photocatalytic activity is successfully formed from ammonium oxofluorotitanate mesocrystals in presence of PEG-6000. For the first time, the phase of potassium hexatitanate from ammonium oxofluorotitanate is achieved by solid-state synthesis at a low temperature of $500{ }^{\circ} \mathrm{C}$. The results of SEM, TEM and SAED show that the growth of potassium titanate $\left(\mathrm{K}_{2} \mathrm{Ti}_{6} \mathrm{O}_{13}\right)$ nanowhiskers occurs oriented to the $001 \mathrm{TiO}_{2}$ plane of the mesocrystals. The obtained material 
demonstrates a photocatalytic activity nearly 2 times higher than that of a standard commercial photocatalyst, Evonik Aeroxide ${ }^{\circledR} \mathrm{TiO}_{2} \mathrm{P} 25$, for the photodegradation reaction of methylene blue. Thus, the methodology described herein opens up the possibility of obtaining $\mathrm{TiO}_{2}-\mathrm{K}_{2} \mathrm{Ti}_{6} \mathrm{O}_{13}$ hybrid materials with high crystallinity and excellent photocatalytic activity for application in, for example, water splitting reactions.

\section{Acknowledgements}

The work was financially supported by the Russian Science Foundation (project N18-73-10212). This study was performed using the equipment of the JRC PMR IGIC RAS and of the Shared Use Centre "Centre of Physical and Physicochemical Methods of Analysis and Study of the Properties and Surface Characteristics of Nanostructures, Materials, and Products" UdmFRC UB RAS". 


\section{References}

[1] E. V. Sturm (née Rosseeva), H. Cölfen, Mesocrystals: structural and morphogenetic aspects, Chem. Soc. Rev. 45 (2016) 5821-5833. https://doi.org/10.1039/C6CS00208K.

[2] H. Cölfen, M. Antonietti, Mesocrystals: Inorganic superstructures made by highly parallel crystallization and controlled alignment, Angew. Chemie - Int. Ed. 44 (2005) 5576-5591. https://doi.org/10.1002/anie.200500496.

[3] O. V. Boytsova, A.A. Sadovnikov, K.E. Yorov, A.N. Beltiukov, A.E. Baranchikov, V.K. Ivanov, X. Zhong, D.J. Lewis, P. O’Brien, A.J. Sutherland, New insights into polymer mediated formation of anatase mesocrystals, CrystEngComm. 19 (2017) 3281-3287. https://doi.org/10.1039/C6CE01985D.

[4] B. Ohtani, O.O. Prieto-Mahaney, D. Li, R. Abe, What is Degussa (Evonic) P25? Crystalline composition analysis, reconstruction from isolated pure particles and photocatalytic activity test, J. Photochem. Photobiol. A Chem. 216 (2010) 179-182. https://doi.org/10.1016/j.jphotochem.2010.07.024.

[5] K. Teshima, K. Yubuta, S. Sugiura, T. Suzuki, T. Shishido, S. Oishi, Flux Growth and Characterization of Photocatalytic Na2Ti6O13 Whiskers, Bull. Chem. Soc. Jpn. 79 (2006) 1725-1728. https://doi.org/10.1246/bcsj.79.1725.

[6] Q. Wang, Q. Guo, B. Li, Low temperature synthesis and characterization of substitutional Na-modified K2Ti6O13 nanobelts with improved photocatalytic activity under UV irradiation, RSC Adv. 5 (2015) 66086-66095. https://doi.org/10.1039/c5ra10640k.

[7] M.A. Siddiqui, V.S. Chandel, A. Azam, Comparative study of potassium hexatitanate (K 2 Ti 6013 ) whiskers prepared by sol-gel and solid state reaction routes, Appl. Surf. Sci. 258 (2012) 7354-7358. https://doi.org/10.1016/j.apsusc.2012.04.018.

[8] W. Zhang, X. Wang, Y. Ma, H. Wang, Y. Qi, C. Cui, Enhanced Photocatalytic and Antibacterial Activities of K2Ti6O13 Nanowires Induced by Copper Doping, Crystals. 10 (2020) 400. https://doi.org/10.3390/cryst10050400.

[9] S. Takaya, Y. Lu, S. Guan, K. Miyazawa, H. Yoshida, H. Asanuma, Fabrication of the photocatalyst thin films of nano-structured potassium titanate by molten salt treatment and its photocatalytic activity, Surf. Coatings Technol. 275 (2015) 260-263. https://doi.org/10.1016/j.surfcoat.2015.05.009.

[10] L.F. Garay-Rodríguez, L.M. Torres-Martínez, Photocatalytic CO2 reduction over A2Ti6O13 (A=Na and K) titanates synthesized by different pH-catalyzed sol-gel, J. SolGel Sci. Technol. 93 (2020) 428-437. https://doi.org/10.1007/s10971-019-05138-5.

[11] X. Zhu, A. Yamamoto, S. Imai, A. Tanaka, H. Kominami, H. Yoshida, A silver-manganese dual co-catalyst for selective reduction of carbon dioxide into carbon monoxide over a 
potassium hexatitanate photocatalyst with water, Chem. Commun. 55 (2019) 13514-13517. https://doi.org/10.1039/c9cc06038c.

[12] H. Yoshida, M. Sato, N. Fukuo, L. Zhang, T. Yoshida, Y. Yamamoto, T. Morikawa, T. Kajino, M. Sakano, T. Sekito, S. Matsumoto, H. Hirata, Sodium hexatitanate photocatalysts prepared by a flux method for reduction of carbon dioxide with water, Catal. Today. 303 (2018) 296-304. https://doi.org/10.1016/j.cattod.2017.09.029.

[13] H. Yoshida, M. Takeuchi, M. Sato, L. Zhang, T. Teshima, M.G. Chaskar, Potassium hexatitanate photocatalysts prepared by a flux method for water splitting, in: Catal. Today, Elsevier, 2014: pp. 158-164. https://doi.org/10.1016/j.cattod.2013.10.046.

[14] M.A. Escobedo Bretado, M.A. González Lozano, V. Collins Martínez, A. López Ortiz, M. Meléndez Zaragoza, R.H. Lara, C.U. Moreno Medina, Synthesis, characterization and photocatalytic evaluation of potassium hexatitanate (K2Ti6O13) fibers, Int. J. Hydrogen Energy. 44 (2019) 12470-12476. https://doi.org/10.1016/j.ijhydene.2018.06.085.

[15] S. Li, C. Wu, Y. Yan, Y. Deng, Study on preparation and performances of TiO2/potassium titanate photocatalyst, in: 2nd Int. Conf. Bioinforma. Biomed. Eng. ICBBE 2008, IEEE Computer Society, 2008: pp. 2853-2856. https://doi.org/10.1109/ICBBE.2008.1045.

[16] $\uparrow$ Ningzhong Bao, $\uparrow$ Xin Feng, $\$$ and Liming Shen, $\uparrow$ Xiaohua Lu*, Calcination Syntheses of a Series of Potassium Titanates and Their Morphologic Evolution, (2002). https://doi.org/10.1021/CG025541+.

[17] N. Bao, L. Shen, X. Feng, X. Lu, High Quality and Yield in Potassium Titanate Whiskers Synthesized by Calcination from Hydrous Titania, J. Am. Ceram. Soc. 87 (2004) 326-330. https://doi.org/10.1111/j.1551-2916.2004.00326.x.

[18] Y. Yu, P.D. Han, L.M. Peng, G.H. Du, Q. Chen, Potassium titanate nanowires: Structure, growth, and optical properties, Phys. Rev. B - Condens. Matter Mater. Phys. 67 (2003) 035323. https://doi.org/10.1103/PhysRevB.67.035323.

[19] X. Zhu, A. Yamamoto, S. Imai, A. Tanaka, H. Kominami, H. Yoshida, Facet-selective deposition of a silver-manganese dual cocatalyst on potassium hexatitanate photocatalyst for highly selective reduction of carbon dioxide by water, Appl. Catal. B Environ. 274 (2020) 119085. https://doi.org/10.1016/j.apcatb.2020.119085.

[20] G.L. Li, G.H. Wang, J.M. Hong, Synthesis and characterization of K2Ti6O13 whiskers with diameter on nanometer scale, J. Mater. Sci. Lett. 18 (1999) 1865-1867. https://doi.org/10.1023/A:1006619910915.

[21] J.H. Choy, Y.S. Han, A combinative flux evaporation-slow cooling route to potassium titanate fibres, Mater. Lett. 34 (1998) 111-118. https://doi.org/10.1016/S0167$577 X(97) 00157-2$. 
[22] M. Shibata, A. Kudo, A. Tanaka, K. Domen, K. Maruya, T. Onishi, Photocatalytic Activities of Layered Titanium Compounds and Their Derivatives for H 2 Evolution from Aqueous Methanol Solution , Chem. Lett. 16 (1987) 1017-1018. https://doi.org/10.1246/cl.1987.1017.

[23] Z. Zhao, X. Chen, A. Chen, G. Huo, H. Li, Preparation of K2Ti6O13/TiO2 bio-ceramic on titanium substrate by micro-arc oxidation, J. Mater. Sci. 44 (2009) 6310-6316. https://doi.org/10.1007/s10853-009-3869-x.

[24] T. Zhang, Q. Chen, L.-M. Peng, Hydrothermal Reaction Mechanism and Pathway for the Formation of $\mathrm{K}_{2} \mathrm{Ti}_{6} \mathrm{O} 13$ Nanowires, Adv. Funct. Mater. 18 (2008) 3018-3025. https://doi.org/10.1002/adfm.200800360.

[25] M. Inoguchi, M. Afzaal, N. Tanaka, P. O'Brien, The poly(ethylene glycol) assisted preparation of NH4TiOF3 mesocrystals and their topotactic conversion to TiO2, J. Mater. Chem. 22 (2012) 25123. https://doi.org/10.1039/c2jm30872j.

[26] J. Feng, M. Yin, Z. Wang, S. Yan, L. Wan, Z. Li, Z. Zou, Facile synthesis of anatase TiO2 mesocrystal sheets with dominant $\{001\}$ facets based on topochemical conversion, CrystEngComm. 12 (2010) 3425-3429. https://doi.org/10.1039/c0ce00070a.

[27] L. Zhou, D. Smyth Boyle, P. O’Brien, Uniform NH4TiOF3 mesocrystals prepared by an ambient temperature self-assembly process and their topotaxial conversion to anatase, Chem. Commun. (2007) 144-146. https://doi.org/10.1039/b611476h.

[28] Y. Liu, Y. Zhang, H. Tan, J. Wang, Formation and anisotropic dissolution behavior of NH4TiOF 3 Mesocrystals, Cryst. Growth Des. 11 (2011) 2905-2912. https://doi.org/10.1021/cg200056h.

[29] B.X. Lei, P. Zhang, M.L. Xie, Y. Li, S.N. Wang, Y.Y. Yu, W. Sun, Z.F. Sun, Constructing hierarchical porous titania microspheres from titania nanosheets with exposed (001) facets for dye-sensitized solar cells, Electrochim. Acta. 173 (2015) 497-505. https://doi.org/10.1016/j.electacta.2015.05.089.

[30] O. Boytsova, I. Dovgaliuk, D. Chernyshov, A. Eliseev, P. O’Brien, A.J. Sutherland, A. Bosak, Polar and non-polar structures of NH 4 tiof 3, J. Appl. Crystallogr. 52 (2019) $23-$ 26. https://doi.org/10.1107/S1600576718016606.

[31] T. Ohsaka, F. Izumi, Y. Fujiki, Raman spectrum of anatase, TiO2, J. Raman Spectrosc. 7 (1978) 321-324. https://doi.org/10.1002/jrs.1250070606.

[32] C.E. Bamberger, G.M. Begun, C.S. MacDougall, Raman Spectroscopy of Potassium Titanates: Their Synthesis, Hydrolytic Reactions, and Thermal Stability, Appl. Spectrosc. 44 (1990) 30-37. https://doi.org/10.1366/0003702904085732.

[33] C.E. Bamberger, G.M. Begun, Sodium Titanates: Stoichiometry and Raman Spectra, J. Am. 
Ceram. Soc. 70 (1987) C-48-C-51. https://doi.org/10.1111/j.1151-2916.1987.tb04963.x.

[34] R.S. Wagner, W.C. Ellis, Vapor-liquid-solid mechanism of single crystal growth, Appl. Phys. Lett. 4 (1964) 89-90. https://doi.org/10.1063/1.1753975. 
Table 1. Parameters of $\mathrm{NH}_{4} \mathrm{TiOF}_{3}$ and $\mathrm{TiO}_{2}$ materials

\begin{tabular}{lccccc}
\hline & $\begin{array}{c}\text { BET, } \\
\mathrm{m}^{2} / \mathrm{g}\end{array}$ & $\begin{array}{c}\text { Planar } \\
\text { size, } \\
\mu \mathrm{m}\end{array}$ & $\begin{array}{c}\text { Thickness, } \\
\mu \mathrm{m}\end{array}$ & $\begin{array}{c}\text { Nanoparticles } \\
\text { size by XRD, } \\
\mathrm{nm}\end{array}$ & $\begin{array}{c}\text { Nanoparticles } \\
\text { size by SEM, } \\
\mathrm{nm}\end{array}$ \\
\hline $\mathrm{NH}_{4} \mathrm{TiOF}_{3}$ & 1 & $2.0-2.5$ & $0.8-1.1$ & & - \\
mesoTiO $_{2}$ after 2 $\mathrm{h}$ & 6 & $2.3-2.9$ & $1.2-1.4$ & $45 \pm 1$ & $30+/-$ \\
mesoTiO $_{2}$ after 4 h & 11 & $2.6-3.2$ & $1.6-1.8$ & $47 \pm 1$ & $40+/-$ \\
mesoTiO $_{2}$ after 8 h & 10 & $3.1-3.8$ & $1.7-2.0$ & $53 \pm 1$ & $90+/-$ \\
\hline
\end{tabular}

Table 2. XPS for $\mathrm{TiO}_{2}$ obtained after 2,4 and 8 hours at $500{ }^{\circ} \mathrm{C}$.

\begin{tabular}{cccccccc}
\hline & $\mathrm{O}$ & $\mathrm{Ti}$ & $\mathrm{K}$ & $\mathrm{F}$ & $\mathrm{Ti} / \mathrm{O}$ & $\mathrm{K} / \mathrm{Ti}$ & $\mathrm{F} / \mathrm{Ti}$ \\
\hline mesoTiO $_{2}$ after 2 h & 50.6 & 21.1 & 14.8 & 13.4 & 0.41 & 0.70 & 0.63 \\
mesoTiO $_{2}$ after 4 h & 52.7 & 20.3 & 14.2 & 12.8 & 0.38 & 0.69 & 0.63 \\
mesoTiO $_{2}$ after 8 h & 60.4 & 23.0 & 14.0 & 2.5 & 0.444 & 0.61 & 0.10 \\
\hline
\end{tabular}

Table 3. EELS for $\mathrm{K}_{2} \mathrm{Ti}_{6} \mathrm{O}_{13}$ obtained after 8 hours at $500{ }^{\circ} \mathrm{C}$.

\begin{tabular}{lccc}
\hline & $\mathrm{K}$ & $\mathrm{Ti}$ & $\mathrm{K} / \mathrm{Ti}$ \\
\hline Spectrum 1 & 18.7 & 81.3 & 0.23 \\
Spectrum 2 & 20.2 & 79.8 & 0.25 \\
Spectrum 3 & 18.3 & 81.8 & 0.22 \\
Spectrum 4 & 20.1 & 79.9 & 0.25 \\
\hline
\end{tabular}




\section{FIGURE CAPTIONS}

Fig. 1. Wide-angle (A) and small-angle (B) powder XRD patterns of hybrid materials based on $\mathrm{TiO}_{2}$-anatase after anneal 2, 4 and 8 hours

Fig. 2. Raman spectra of hybrid materials obtained after annealing for 2,4 and 8 hours at $500{ }^{\circ} \mathrm{C}$.

Fig. 3. HRTEM (A) and SAED pattern (B) images for the $\mathrm{TiO}_{2}$ mesocrystal obtained after annealing for 4 hours at $500{ }^{\circ} \mathrm{C}$

Fig. 4. SEM images of $\mathrm{NH}_{4} \mathrm{TiOF}_{3}(\mathrm{~A})$ and hybrid materials based on $\mathrm{TiO}_{2}$-anatase after annealing for 2 (B), 4 (C) and 8 (D) hours at $500{ }^{\circ} \mathrm{C}$

Fig. 5. HRTEM and SAED pattern images for the $\mathrm{K}_{2} \mathrm{Ti}_{6} \mathrm{O}_{13}$ nanowhiskers

Fig. 6. TEM image of a single $\mathrm{K}_{2} \mathrm{Ti}_{6} \mathrm{O}_{13}$ whisker obtained after heating ammonium oxofluorotitanate for 8 hours at $500{ }^{\circ} \mathrm{C}$

Fig. 7. Methylene blue dye photodecomposition rates in the absence and presence of various samples of titanium dioxide (after annealing for 2, 4 and 8 hours at $500{ }^{\circ} \mathrm{C}$ ) and reference material - Evonik Aeroxide ${ }^{\circledR} \mathrm{TiO}_{2} \mathrm{P} 25$

Fig. 8. First-order reaction kinetics plots of methylene blue dye photodecomposition rates. 

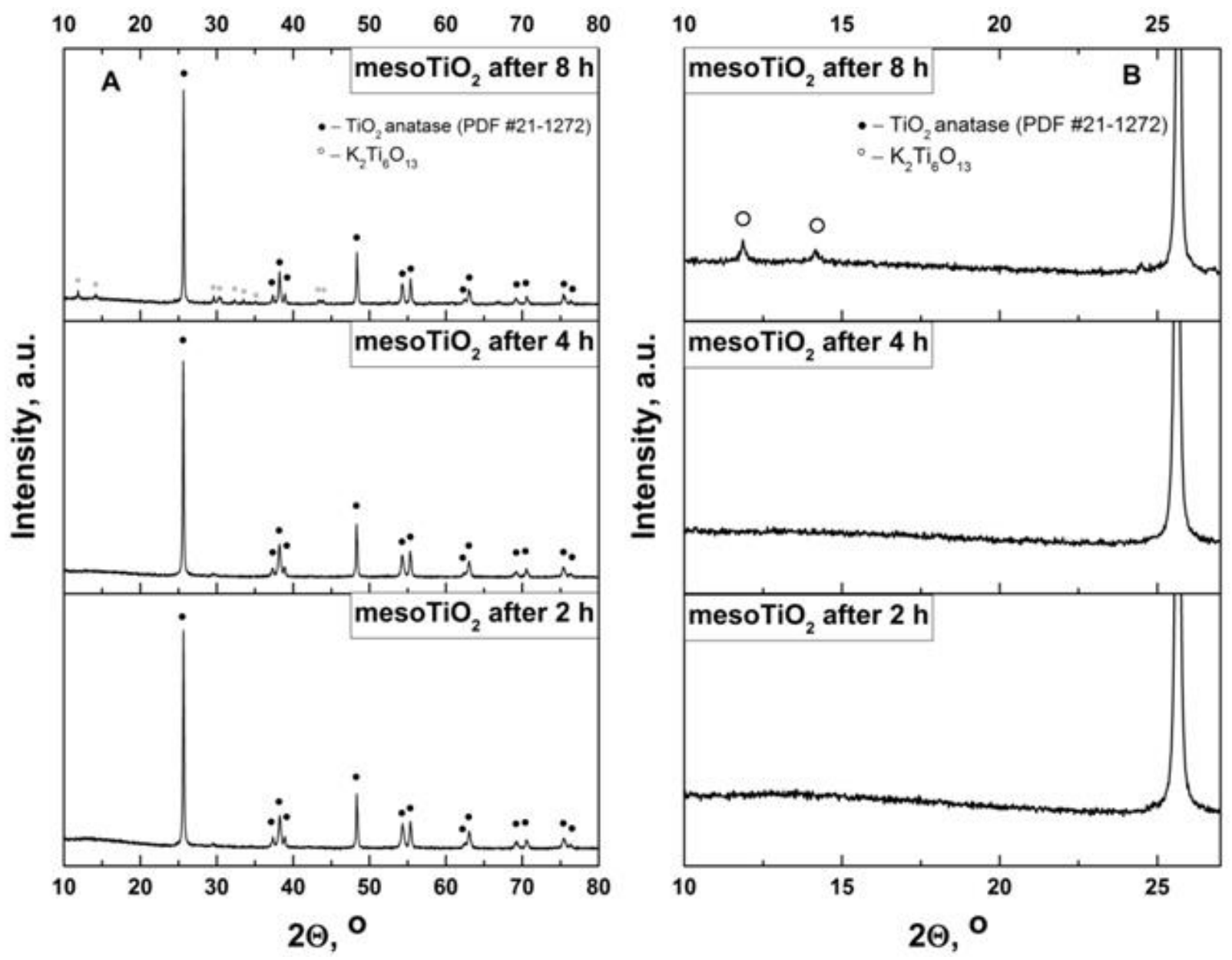

Fig. 1. 

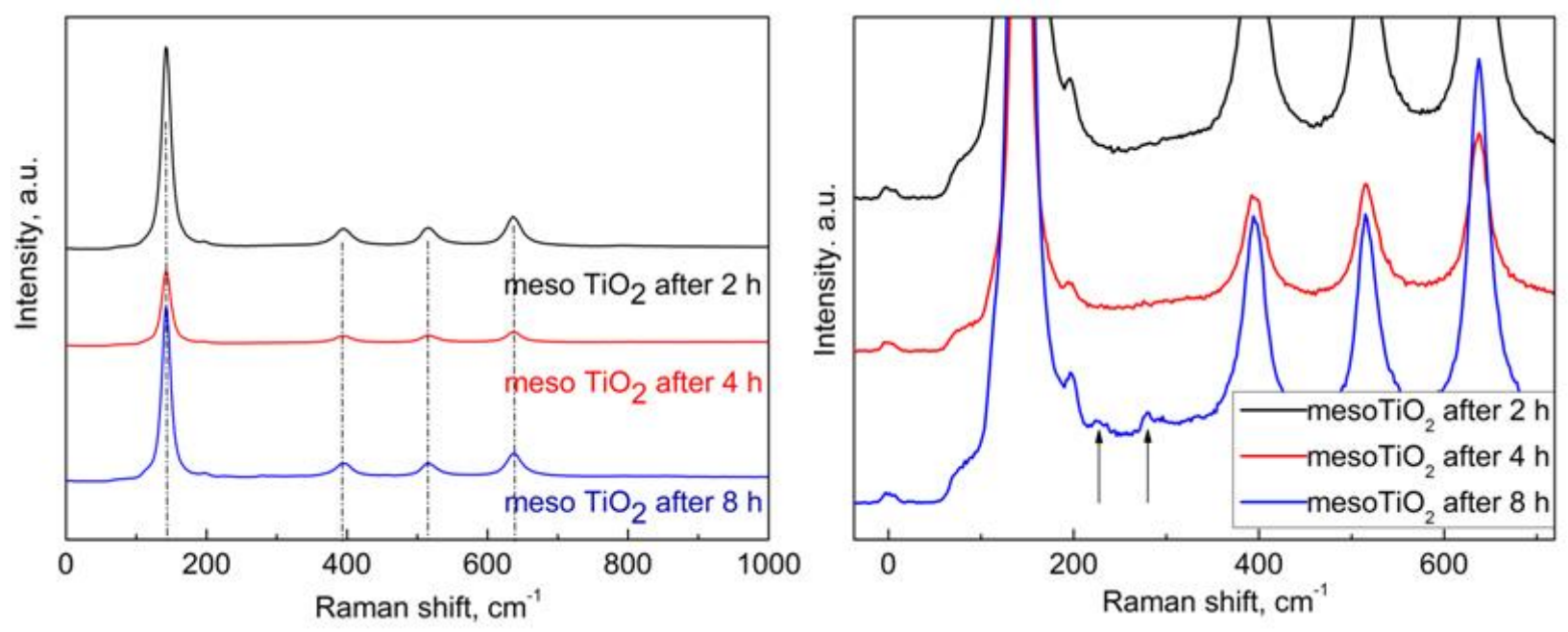

Fig. 2. 


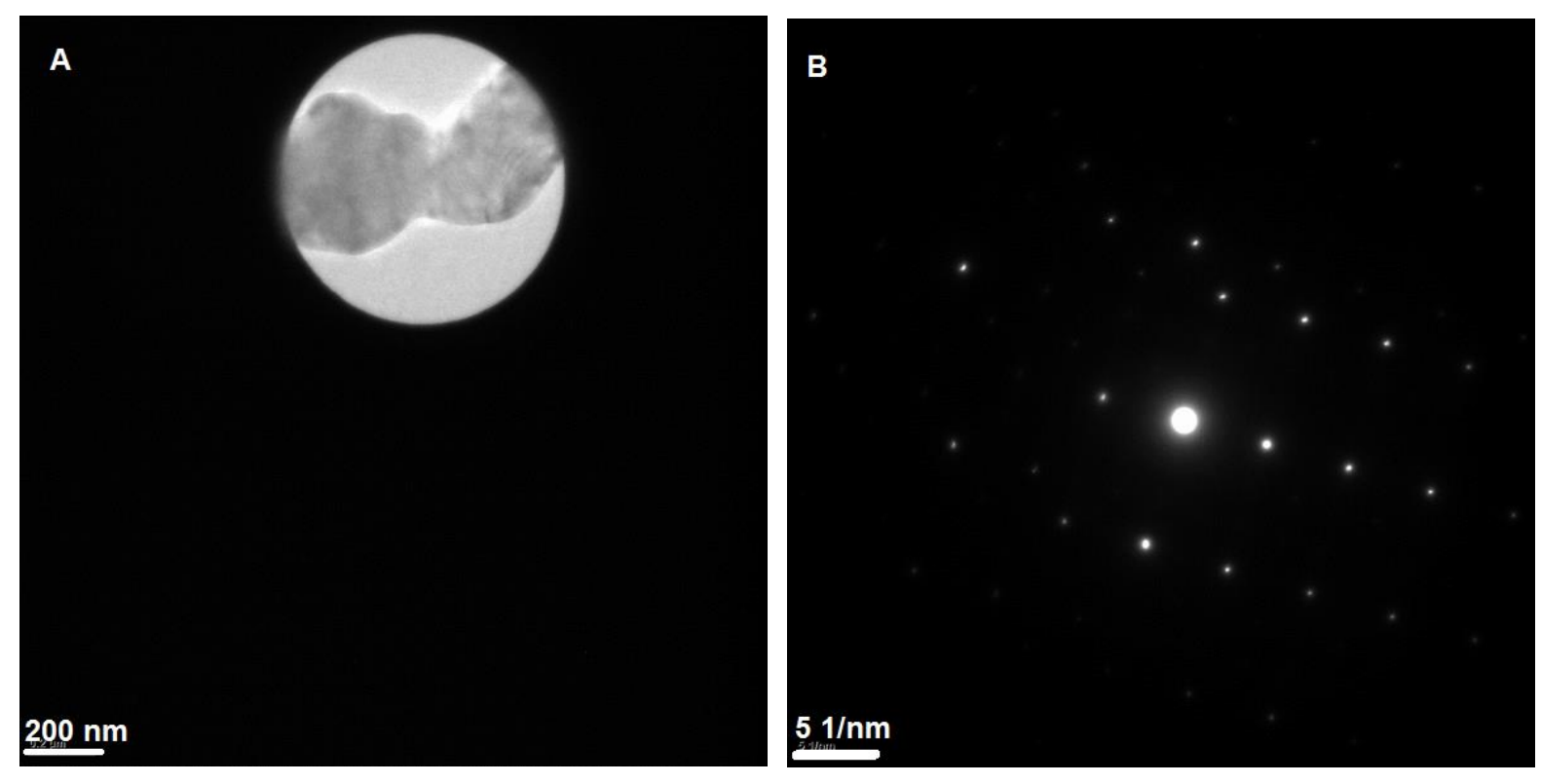

Fig. 3. 


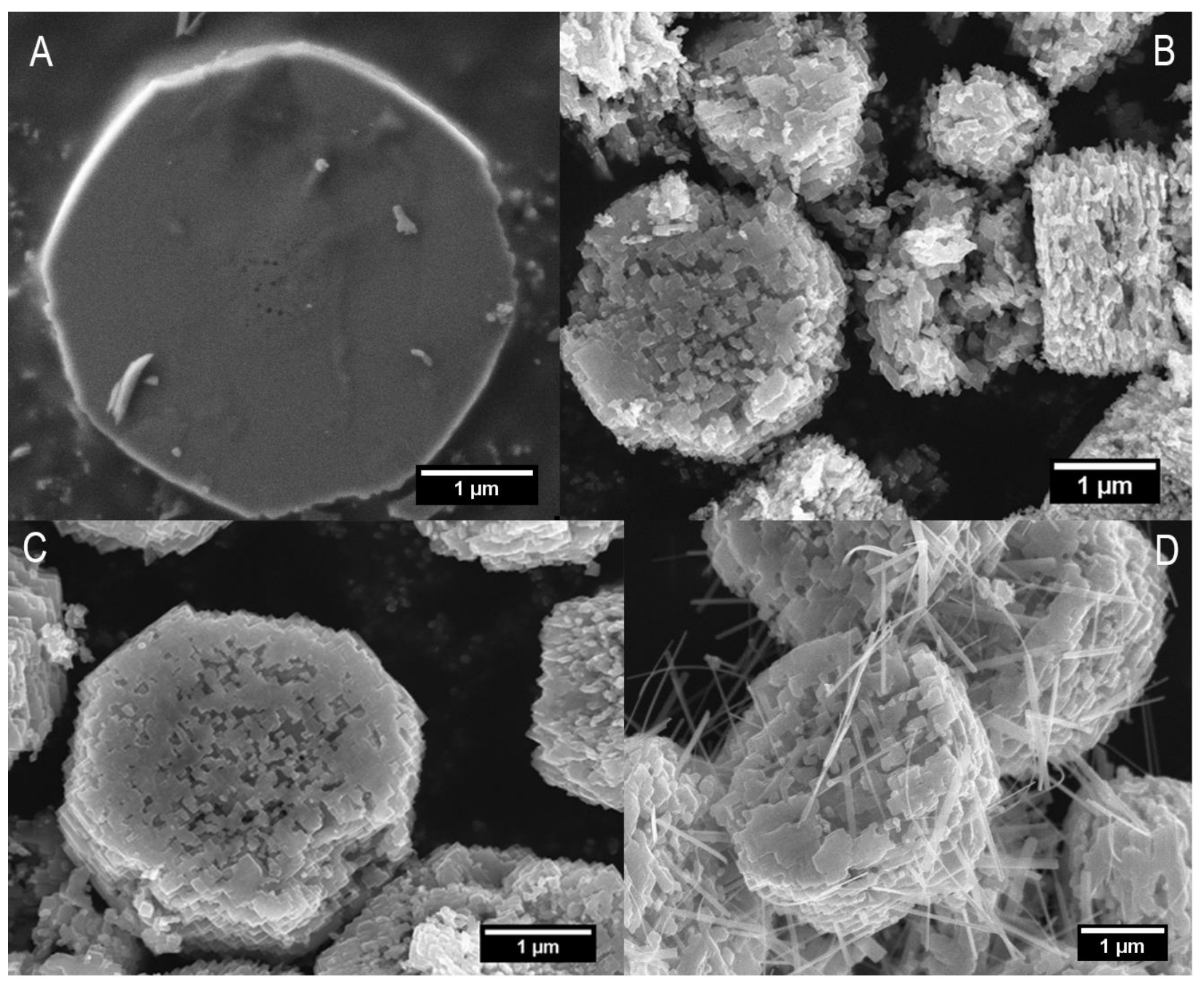

Fig. 4. 

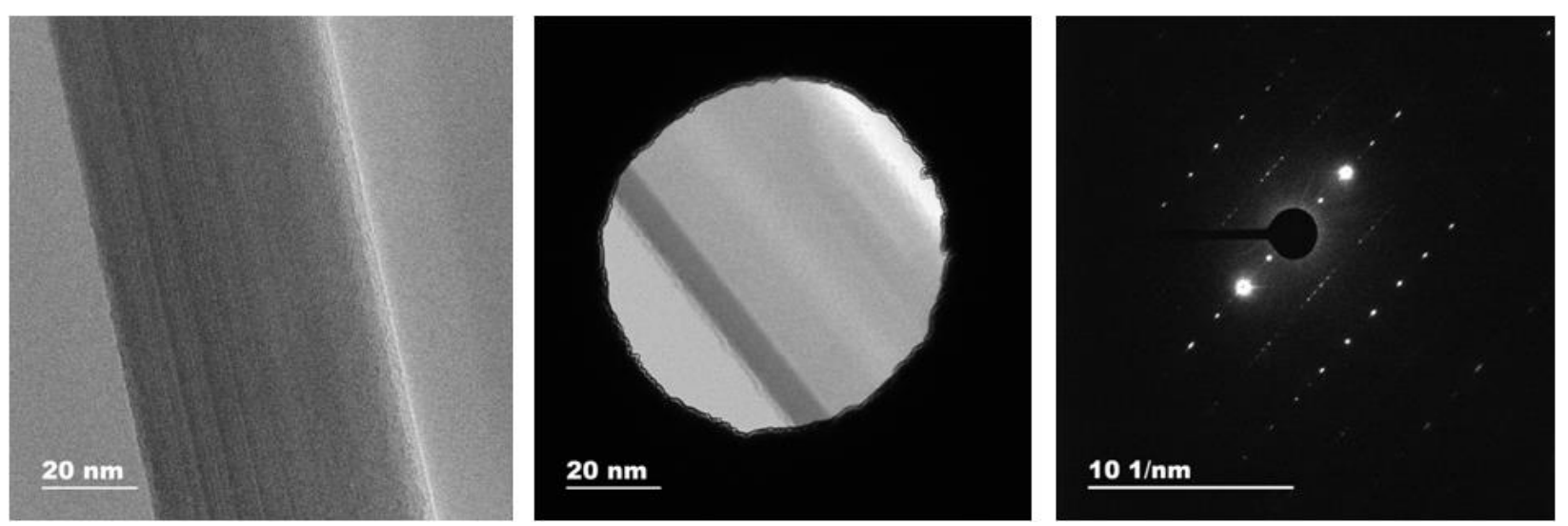

Fig. 5. 


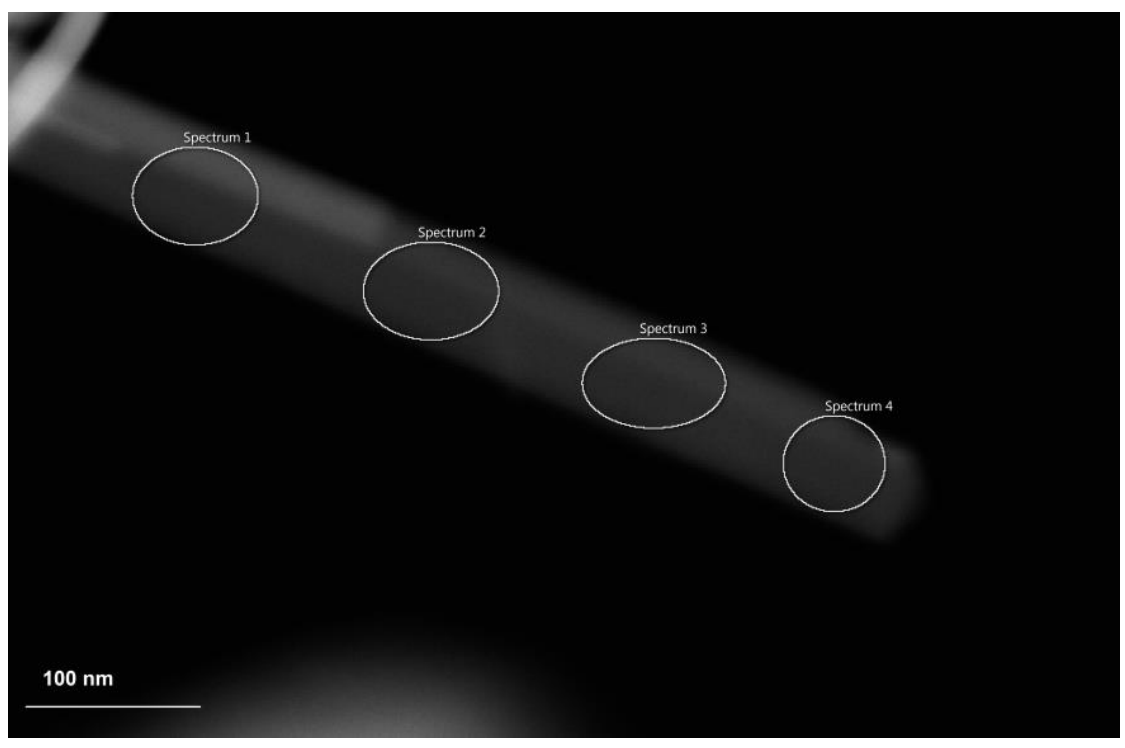

Fig. 6. 


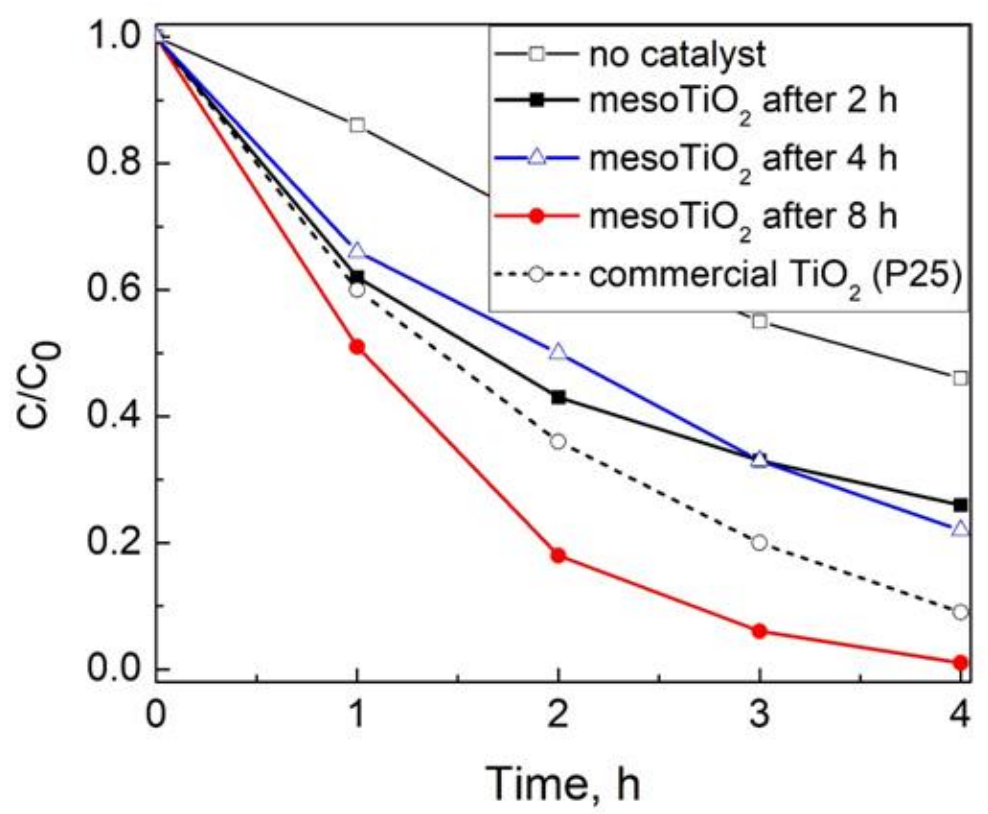

Fig. 7.

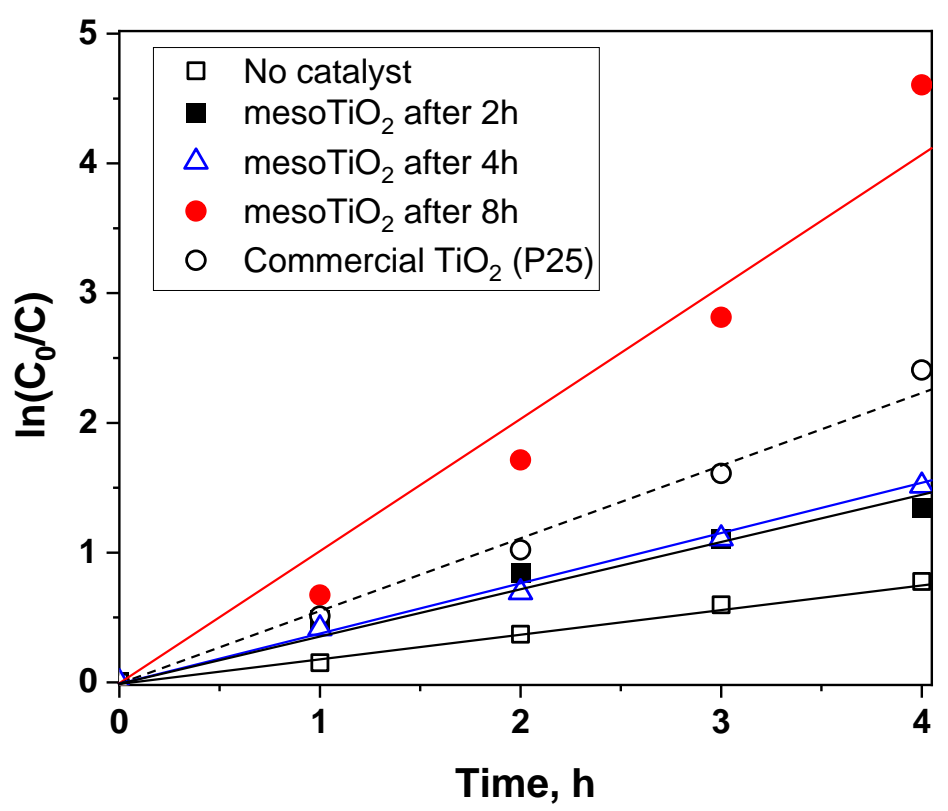

Fig. 8 